\title{
Dispositional achievement motives matter for autonomous versus controlled motivation and behavioral or affective educational outcomes
}

\author{
Aikaterini Michou $^{\mathrm{a}, *}$, Elias Matsagouras ${ }^{\mathrm{b}, 1}$, Willy Lens ${ }^{\mathrm{c}, \mathrm{d}, 2}$ \\ a Bilkent University, Graduate School of Education, 06800 Bilkent, Ankara, Turkey \\ ${ }^{\mathrm{b}}$ University of Athens, Department of Primary Education, Ippokratous 20, 10680 Athens, Greece \\ ' University of Leuven, Department of Psychology, Tiensestraat 102, B 3000 Leuven, Belgium \\ ${ }^{\mathrm{d}}$ University of the Free State, Bloemfontein, South Africa
}

\section{A R T I C L E I N F O}

\section{Article history:}

Received 21 February 2014

Received in revised form 1 June 2014

Accepted 3 June 2014

\section{Keywords:}

Need for achievement

Fear of failure

Autonomous motivation

Controlled motivation

\begin{abstract}
A B S T R A C T
The present study investigated whether autonomous and controlled situational achievement motivation function as mediating processes through which dispositional achievement motives are manifested in affective and behavioral outcomes. Structural Equation Modeling with three student samples (Greek $N=440$; Belgian $N=283$; German $N=264$ ) indicated that need for achievement related positively to positive affect and adaptive studying strategies via autonomous motivation. In contrast, fear of failure related positively to negative affect and negatively to adaptive studying strategies via controlled motivation. Additionally, dispositional achievement motives were directly related to affect outcomes verifying their affect-base as argued in achievement motivation theory. The importance of individual differences in achievement motive dispositions for situational autonomous and controlled motivation is discussed.
\end{abstract}

(c) 2014 Published by Elsevier Ltd.

\section{Introduction}

The last 15 years, the achievement goal perspective has incorporated the classic approach of dispositional achievement motives (McClelland, Atkinson, Clark, \& Lowell, 1953) into a hierarchical achievement motivation model (Elliot \& Church, 1997) in which need for achievement and fear of failure are considered as the energizers of achievement behavior that manifest through the pursuit of achievement goals (Elliot, 2006). The hierarchical model focuses on the links between the two dispositional achievement motives and the adopted achievement goals, or the "what" of achievement goal striving. However, an equally important motivational variable concerns the reasons underlying the engagement in achievement behavior, that is, the "why" of goal striving (Vansteenkiste, Mouratidis, \& Lens, 2010). The links between the dispositional achievement motives and the "why" of achievement striving have been scarcely investigated (see Sheldon \& Cooper, 2008). Can we claim that the effects of need for achievement and fear of failure on achievement outcomes can also be mediated by the "why" of achievement striving? In this study we recruited

\footnotetext{
* Corresponding author. Tel.: +90 3122902910.

E-mail addresses: aliki.michou@bilkent.edu.tr (A. Michou), ematsag@primedu. uoa.gr (E. Matsagouras), Willy.Lens@psy.kuleuven.be (W. Lens).

1 Tel.: +302103688472.

2 Tel.: +32 (0)16325971.
}

three samples coming from different countries (i.e., Greece, Belgium and Germany) and educational settings (i.e., high school and university) and investigated the neglected relation of dispositional achievement motives to autonomous and controlling reasons for engagement in achievement behavior as these are operationally defined by the Self-determination theory (SDT; Deci \& Ryan, 2000). We also examined the direct and indirect (through autonomous versus controlling reasons) relations of need for achievement and fear of failure to students' affective and behavioral outcomes. Similarities and differences among the three different samples of the present study will further clarify the possibility to generalize the obtained results.

\subsection{Achievement motives and autonomous versus controlled motivation}

In achievement motivation theory, need for achievement and fear of failure are defined as acquired motivational dispositions to, respectively, approach success and avoid failure. Need for achievement has been defined as the basis of an appetitive tendency to strive for success, and fear of failure as the origin of an inhibitory tendency to avoid failure (Atkinson \& Feather, 1966). Atkinson (1964) defines the strength of situational achievement motivation as the product of need for achievement (or fear of failure), the probability of success (or failure), and the anticipated value of the success (or failure). There are situations where the 
probability of success (a potential intrinsic component) is high and the value is reflected through receiving a contingent reward (an extrinsic component). In such situations the total motivation is high, yet pressuring because of the extrinsic component. Thus the quality (and not only the strength) of the total achievement motivation in terms of volitional (autonomous) or pressuring (controlling) incentives is important to be taken into consideration as it could have unique links with the more general motive dispositions (i.e., the need for achievement and fear of failure).

A student with a high need for achievement (and a low fear of failure) is oriented toward success in achievement tasks. For such a student, task engagement could be more pleasurable or personally important because her engagement serves as a means to attain success. According to SDT, an inherent pleasure in an activity requires an intrinsic motive, whereas a personally important activity presupposes an identified motive, both forms of autonomous motivation (Deci \& Ryan, 2000).

A student with a high fear of failure (and a low need for achievement) is oriented toward the avoidance of achievement tasks. However, when such a student cannot avoid such a threatening situation, (e.g., obligatory assignments at school or high-stakes final exams at the University) she is more likely to engage in a task because of a strong extrinsic (i.e., controlled) motivation (e.g., to obey parents (i.e., external motives), or to avoid feelings of guilt (i.e., introjected motive)). SDT classifies these types of motives as controlled motivation.

Need for achievement and fear of failure establish in childhood through parenting practices that provoke particular affective responses (McClelland, 1987). Hence, achievement motives are inherently not only competence-based but also relational- and affect-based dispositions (Elliot \& Thrash, 2004). Parents and other socializing agents (e.g., teachers) play an important role in the formation of achievement-related motives (Winterbottom, 1958) as through the provided competence-related feedback they can elicit to a child feelings of pride (after successful accomplishments) or shame (after failures).

The affective base of achievement motives could be an additional factor that may improve or impair the integration of the behavior into the self and thus may promote or inhibit autonomous motivation. One who has acquired a general capacity to take pride in accomplishment is more likely to perceive one's behavior or values in a specific context as instigated by the true self (i.e., autonomous motivation). Pride is the result of a behavior dictated by the self. In contrast, one who has acquired a general capacity to feel shame due to failure is more likely to be receptive to external or to internal pressuring incentives like guilt (i.e., controlled motivation).

This reasoning leads to the assumption that need for achievement facilitates the integrative process of the inner and outer world and thus is linked with autonomous motivation. It also leads to the hypothesis that fear of failure inhibits organismic integration and therefore is linked with controlled motivation. Sheldon and Cooper (2008) found need for achievement to relate to autonomous (but not to controlled) motivation when competence-based role-goals (e.g., at school) were adopted. However fear of failure has not been investigated and it remains underexplored if it instigates controlled motivation.

In the present study we aimed to investigate in educational settings the neglected relation between dispositional achievement motives and autonomous versus controlled students' motivation. We focused on educational settings because in such contexts individuals cannot avoid task engagement. Therefore, we expected that achievement motivation for those high in fear of failure would manifest through controlled motivation. We also examined the mediating role of autonomous versus controlled motivation between dispositional achievement motives and students' positive/negative affect, anxiety (i.e., affective outcomes), time management and test strategy (i.e., behavioral outcomes).

\subsection{Educational correlates of achievement motives}

The need for achievement has been linked through approach achievement goals (Elliot \& McGregor, 2001) to numerous positive educational outcomes, including intrinsic motivation, optimal performance, self-regulatory strategies, and positive feelings (Urdan, 1997). In contrast, fear of failure is considered to lead to task avoidance, performance avoidance goals and various negative educational outcomes like underperformance and decreased intrinsic motivation. Unlike the theory of achievement motivation (Atkinson \& Feather, 1966), the achievement goal perspective argues that fear of failure can lead also to the adoption of performanceapproach goals as an attempt to avoid failure (Elliot \& McGregor, 2001). However, when the direct relation of fear of failure to outcomes was investigated, fear of failure was associated positively to behavioral problems and negatively to school engagement and academic competence (Caraway, Tucker, Reinke, \& Hall, 2003). It seems that need for achievement and fear of failure are, respectively, positive and negative predictors of students' optimal functioning.

\subsection{The present study}

We aimed to investigate the relation of explicit measures of need for achievement and fear of failure to autonomous and controlled motivation in educational settings. Following the reasoning that need for achievement facilitates the organismic integration of the inner and outer world, we hypothesized a positive relation between need for achievement and autonomous motivation. Assuming also that fear of failure instigates pressure for someone who cannot avoid a threatening achievement situation, we hypothesized a positive relation between fear of failure and controlled motivation. We presumed that high school students cannot but undertake homework and that university students cannot but take final exams. Although we believe that challenging tasks (assignments or final exams) might have different connotations for high school and university students, we presumed that fear of failure engenders similar process in both contexts that is controlled motivation.

We also aimed to investigate the relations of achievement motives to affective and behavioral outcomes. Regarding the affective outcomes, we assumed that need for achievement and fear of failure, given their affective base, would relate not only indirectly (through autonomous versus controlled motivation, respectively) but also directly to positive and negative affect and anxiety. There are two additional reasons to expect such direct relationships. First, because need for achievement implies a behavioral activation system which is likely to generate positive affect while fear of failure denotes a behavioral inhibition system that is likely to generate negative affect (Gray, 1994). Second, because the scale of achievement motivation that we used to assess achievement motivation taps to some extent affect experiences emerging in achievement situations.

Regarding the behavioral outcomes, we hypothesized only an indirect relation of achievement motives to time management and test strategy. This hypothesis of indirect relation is justified by the competence-base nature of approaching success or avoiding failure which demands a more strategic cognitive-motivational process in order to be guided to particular behavior (Elliot, 2006). Therefore, in our study we considered autonomous and controlling regulations as the necessary strategic cognitive-motivational processes through which achievement motives are channeled to behavioral outcomes. Specifically, we hypothesized that need for achievement will relate positively to adaptive study strategies (i.e., time management and test strategy) through autonomous motivation as previous studies have shown that autonomous 
motivation is related to deep learning, time management, concentration, and persistence (Reeve, Deci, \& Ryan, 2004). Similarly, we hypothesized an indirect negative relation of fear of failure to adaptive study strategies through controlled motivation as the latter has been linked with anxiety, maladaptive coping strategies, superficial learning, and school dropout (Reeve et al., 2004).

To test our hypothesis we surveyed two samples of university students from Greece, and Belgium and a sample of high school students from Germany. The hypothesized models for affect and study strategies depicted in Figs. 1 and 2 respectively, were common for the three samples as differences in the relationship of autonomous and controlled motivation with other variables across different cultures and settings have not been supported by research in SDT (Ryan \& Deci, 2006).

\section{Method}

\subsection{Participants and procedure}

Participants were 440 Greek second and third year university students of a Department of Education $\left(M_{\mathrm{age}}=20.5, S D=2.80\right.$; 90.9\% females; 5 students omitted reporting their gender), 283 Belgian first year university students of a Psychology Department (main range age 17-18 years old; $47.3 \%$ females; 2 students omitted reporting their gender) and 264 German high school students (main range age 15-18 years old; 20.5\% 10th grade, 23.1\% 11th grade, $28.4 \% 12$ th grade, $27.3 \% 13$ th grade, 2 students omitted reporting their grade; $46.2 \%$ females; 5 students omitted reporting their gender). The three samples come from institutions located in urban regions.

Students participated voluntary and anonymously in the surveys during a class session. The measures were the same in the three samples and were adjusted according to culture and context. For example, university students in Greece use to be evaluated by a final exam and not by assignments so we focused the scales more on studying for the finals than for regular homework. All the items were presented in 5-point Likert type scales (1 [Strongly disagree] to 5 [Strongly agree]) and were independently translated by two experts in the field and adjusted according to the procedures proposed by Hambleton (1994).

\subsection{Measures}

\subsubsection{Motive dispositions}

We used the short-version of the Achievement Motivation Scale (AMS; Lang \& Fries, 2006) to assess need for achievement (5 out of
15 items of the origin AMS; e.g., "I like situations in which I can find out how capable I am") and fear of failure (5 out of 15 items of the origin AMS; e.g., "Even if nobody would notice my failure, I'm afraid of tasks, which I'm not able to solve"). We chose this shortened measure because, first, it prevents participants' overloading. Second, the fear of failure items focus more on the anxiety-related component of fear of failure and less on the shame-based component which could overlap with introjected regulation, a component of controlled motivation. Third, it ensures a lower correlation between need for achievement and fear of failure and a better fit to the theoretical two factor model (Lang \& Fries, 2006).

\subsubsection{Autonomous versus controlled motivation}

We adapted the Self-Regulation Questionnaire (Ryan \& Connell, 1989) to assess autonomous and controlled students' motivation. Four intrinsic (e.g., "because I like studying"), and four identified regulation items (e.g., "because it is important to me") assessing the reasons for studying were averaged to create an autonomous motivation score, whereas four introjected (e.g., "because I will feel guilty if I don't") and four external regulation items (e.g. "because my parents told me that I have to do it") were averaged to create a controlled motivation score.

\subsubsection{Positive and negative affect}

We used PANAS (Watson, Clark, \& Tellegen, 1988) to assess students' positive (10 items, e.g., "enthusiastic") and negative (10 items, e.g., "irritated") affect toward their studies during the last two weeks.

\subsubsection{Learning and study strategies}

We used three subscales of the LASSI (Weinstein \& Palmer, 2002 ) to assess Belgians and Germans' time management (8 items, e.g., "I find it hard to stick to a study schedule"), test strategies (8 items, e.g., "I review my answers on essay tests to make sure I have made and supported my main points.") and anxiety (8 reverse scored items, e.g., "When I am studying, worrying about doing poorly in a course interferes with my concentration.").

\section{Results}

\subsection{Preliminary analyses}

Descriptive statistics, Cronbach alphas, and bivariate correlations of the measured variables appear in Table 1. A MANOVA showed significant gender differences in the Greek (Wilk's $\Lambda=.927, F[6,424]=5.57, p<.01$, multivariate $\eta^{2}=.07$ ), Belgian
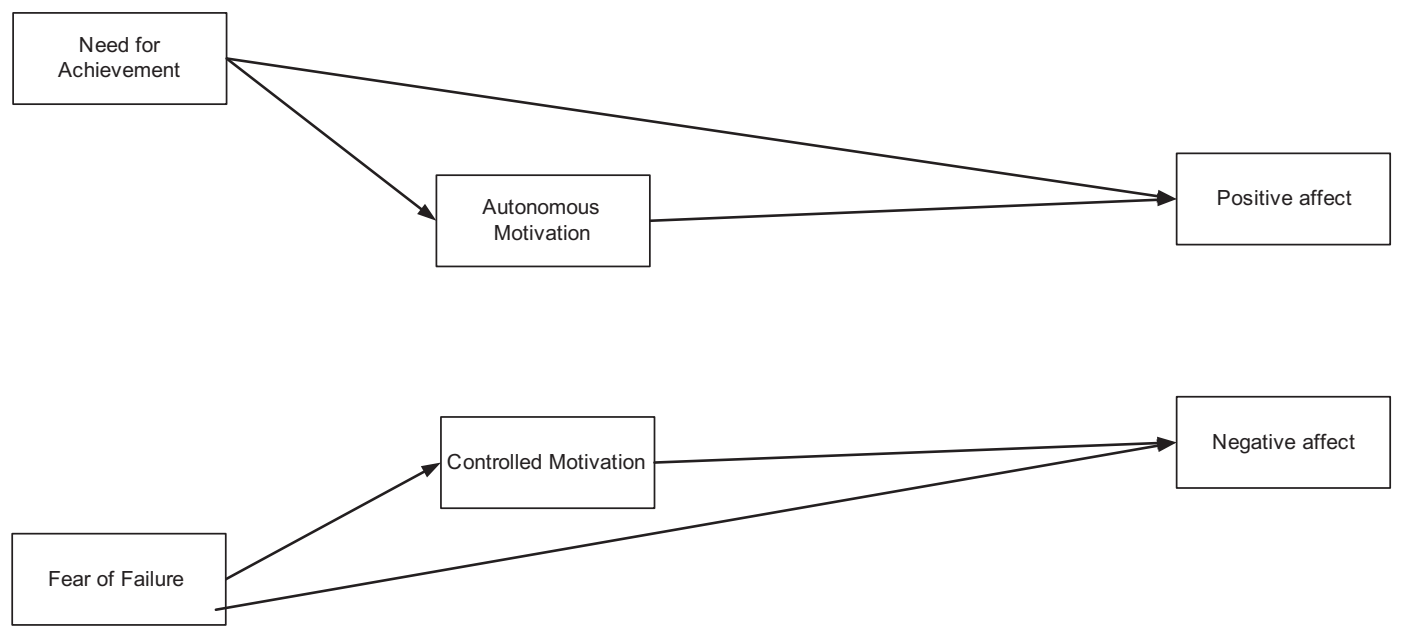

Fig. 1. The hypothesized model for affect outcomes. 


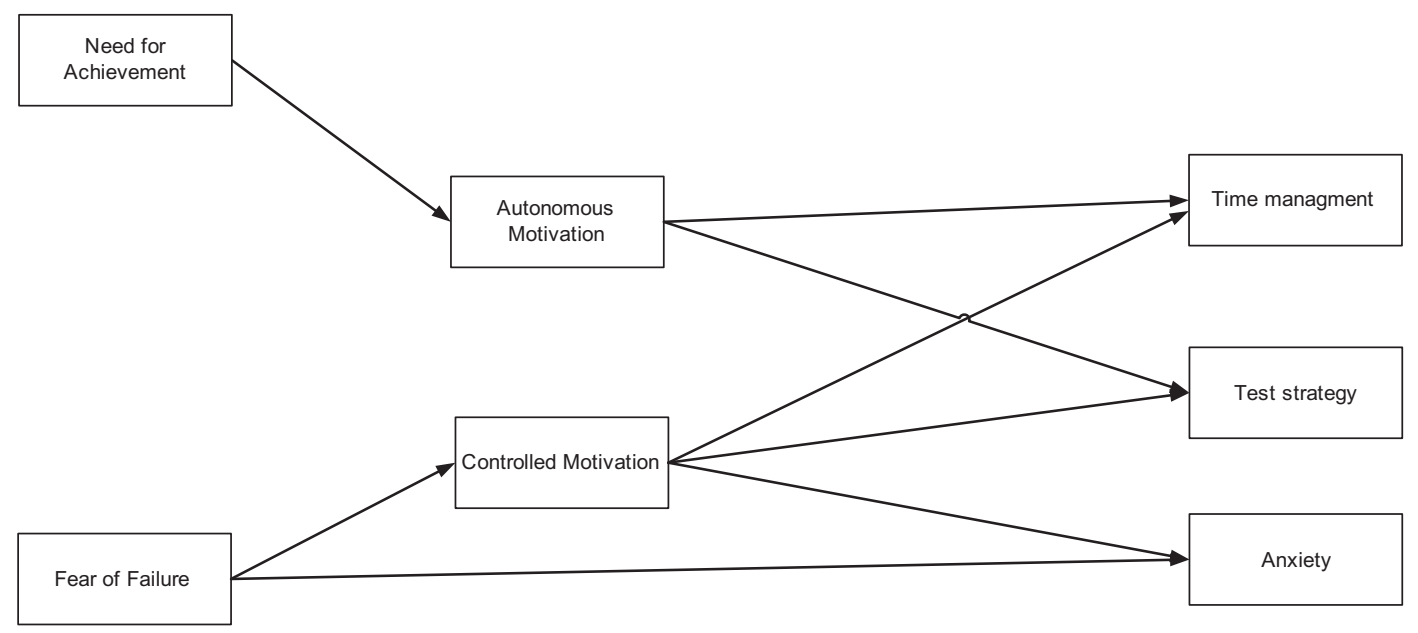

Fig. 2. The hypothesized model for study strategies outcomes.

(Wilk's $\Lambda=.839, F[9,255]=5.42, p<.01$, multivariate $\eta^{2}=.16$ ) and German (Wilk's $\Lambda=.813, F[9,241]=6.15, p<.01$, multivariate $\left.\eta^{2}=.19\right)$ samples. A follow-up ANOVA with a Bonferroni correction, showed that Greek males, as compared to females, scored lower in autonomous motivation $F(1,430)=7.99, \quad p<.005$, $\eta^{2}=.02(M=4.04, S D=0.57$ versus $M=3.75, S D=0.64)$ and higher in negative affect $F(1,430)=12.00, p<.001, \eta^{2}=.03 . \quad(M=2.24$, $S D=0.84$ versus $M=1.81, S D=0.68$ ). Also, Belgian males, compared to females, scored lower for fear of failure $F(1,265)=18.62$, $p<.001, \eta^{2}=.07(M=2.92, S D=0.71$ versus $M=3.29, S D=0.67)$ and the same was true for the German males $(F[1,250]=25.15$, $p<.01, \eta^{2}=.01 ; M=2.06, S D=0.57$ versus $M=2.47, S D=0.71$ ) who showed also lower score in positive affect $(F[1,250]=9.90$, $p<.01, \eta^{2}=.04 ;(M=2.98, S D=0.61$ versus $M=3.23, S D=0.67)$ and anxiety $F(1,250)=15.27, p<.01, \eta^{2}=.06 .(M=3.08, S D=0.69$ versus $M=3.42, S D=0.69$ ). Therefore, gender was included as a covariate in the subsequent analyses.

\subsection{Main analyses}

We used Structural Equation Modeling (SEM) with EQS program to investigate for each sample separately the mediating role of autonomous and controlled motivation on the relation of dispositional achievement motives to affect and study strategies. In all models, we used parcel indicators (two parcels for all latent variables, except study strategies where we used three parcels) to keep the ratio of the number of observations to the number of estimated parameters to a reasonable level (Bentler \& Chou, 1987). In each parcel indicator we imposed an equality constraint to their error variance to properly identify the model (Kline, 2005).

The structural model for affect outcomes showed reasonable fit across the three samples (see Table 2). As can be seen (Fig. 3), need for achievement was positively related to autonomous motivation which in turn was positively related to positive affect whereas fear of failure was positively correlated to controlled motivation which

Table 1

Means, standard deviations, Cronbach alphas, and bivariate correlations of the measured variables for the three samples.

\begin{tabular}{|c|c|c|c|c|c|c|c|c|c|}
\hline Variables & 1 & 2 & 3 & 4 & 5 & 6 & 7 & 8 & 9 \\
\hline \multicolumn{10}{|l|}{ Antecedents } \\
\hline 1. Need for achievement & - & & & & & & & & \\
\hline 2. Fear of failure & $.05 / .04 /-.12$ & - & & & & & & & \\
\hline \multicolumn{10}{|l|}{ Motivational variables } \\
\hline $\begin{array}{l}\text { 3. Autonomous } \\
\text { motivation }\end{array}$ & $.25 / .29 / .26$ & $-.04 / .06 / .15$ & - & & & & & & \\
\hline 4. Controlled motivation & $-.05 / .12 / .03$ & $.15 / .31 / .40$ & $\begin{array}{l}-.13 /-.19 / \\
.26\end{array}$ & - & & & & & \\
\hline \multicolumn{10}{|l|}{ Outcomes } \\
\hline 5. Positive affect & $.35 / .19 / .20$ & $\begin{array}{l}-.15 /-.16 / \\
-.20\end{array}$ & $.36 / .46 / .27$ & $\begin{array}{l}-.08 /-.10 / \\
-.07\end{array}$ & - & & & & \\
\hline 6. Negative affect & $\begin{array}{l}-.08 /-.01 / \\
-.09\end{array}$ & $.32 / .42 / .35$ & $\begin{array}{l}-.13 /-.05 / \\
.07\end{array}$ & $.23 / .28 / .39$ & $\begin{array}{l}-.32 /-.24 / \\
-.05\end{array}$ & - & & & \\
\hline 7. Anxiety & $.05 / .05 /-$ & $-.53 /-.56 /-$ & $.05 /-.17 /-$ & $-.34 /-.51 /-$ & $.26 / .17 /-$ & $-.60 /-.40 /-$ & - & & \\
\hline 8. Test strategy & $.09 / .05 /-$ & $-.33 /-.36 /-$ & $.30 /-.15 /-$ & $-.37 \mid-.32 /-$ & $.30 / .14 /-$ & $-.37 \mid-.47 /-$ & $.54 / .54$ & - & \\
\hline 9. Time management & $-.01 / .02 /-$ & $-.03 /-.08 /-$ & $.33 / .32 /-$ & $-.20 / .06 /-$ & $.15 / .18 /-$ & $-.14 /-.23 /-$ & $.16 / .13$ & $.44 / .23$ & - \\
\hline \multirow[t]{2}{*}{ M } & $4.19 / 3.52 / 3.08$ & $3.55 / 3.09 / 2.26$ & $4.02 / 3.29 /$ & $1.89 / 2.71 / 2.58$ & $3.00 / 3.48 / 3.11$ & $1.84 / 2.78 /$ & $3.12 /$ & $3.65 /$ & $2.96 /$ \\
\hline & & & 2.85 & & & 2.01 & 3.25 & 3.66 & 2.96 \\
\hline \multirow[t]{2}{*}{ SD } & $0.52 / 0.61 / 0.50$ & $0.81 / 0.69 / 0.68$ & $0.57 / 0.71 /$ & $0.68 / 0.68 / 0.72$ & $0.82 / 0.68 / 0.64$ & $0.71 / 0.82 /$ & $0.71 /$ & $0.55 /$ & $0.69 /$ \\
\hline & & & 0.72 & & & 0.70 & 0.71 & 0.59 & 0.62 \\
\hline Cronbach alpha & $.81 / .81 / .70$ & $.85 / .74 / .79$ & $.78 / .89 / .85$ & $.76 / .83 / .78$ & $.90 / .78 / .83$ & $.84 / .75 / .85$ & $.84 / .77$ & $.75 / .76$ & $.82 / .63$ \\
\hline
\end{tabular}

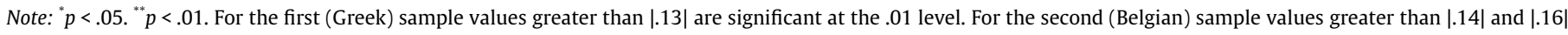
are, respectively, significant at the .05 and .01 level. The respective values for the third (German) sample are |.13| and |.17|. 
in turn was positively related to negative affect. Supplementary analyses showed that the model would yield improved fit indices if need for achievement and fear of failure were allowed to directly relate to affect outcomes (see Fig. 3). A test of indirect effects further showed that need for achievement was associated positively to positive affect $(\beta=.06 / .16 / .11, z=2.69 / 3.78 / 2.65, p<.01 /$ $.01 / .01$ ) by means of autonomous motivation, whereas fear of failure was positively associated to negative affect $(\beta=.04 / 07 / .17$, $z=2.37 / 2.14 / 3.12, \quad p<.01 / .01 / .01)$ by means of controlled motivation.

Regarding the model for study strategies outcomes (Fig. 4), need for achievement was positively related to autonomous motivation which in turn was positively related to time management (in both samples) and to test strategy (in the Belgian sample). In contrast, fear of failure was positively related to controlled motivation which in turn was negatively related to test strategy, anxiety (in both samples), and to time management (in the Belgian sample). In addition, there were direct negative paths from fear of failure to anxiety for both samples. A test of indirect effects showed that need for achievement was associated positively to time management for Belgians and Germans $(\beta=.10 / .15, z=3.29 / 2.80, p<.01 /$ $.01)$ and test strategy for Belgians $(\beta=.08, z=2.65, p<.026)$ by means of autonomous motivation, whereas fear of failure was negatively associated to time management for Belgians $(\beta=-.06$, $z=-2.02, p<.01)$ and test strategy for Belgian and Germans $(\beta=-.17 /-.22, z=-3.87 /-3.89, p<.01 / .01)$ by means of controlled motivation. Also fear of failure was negatively associated to anxiety (reverse scored) through controlled motivation $(\beta=-.10 /-21$, $z=-3.06 /-3.97, p<.01 / .01$ ) for both samples.

A test of group invariance (configural, metric, and factor covariances group invariance test; see Vandenberg \& Lance, 2000) for the affect model (Fig. 3) showed reasonable fit $\left(S-B \chi^{2}[279]=\right.$ 658.27, $p<.01, \mathrm{CFI}=.928$, SRMR $=.092, \mathrm{RMSEA}=.066[90 \% \mathrm{CI}$ : $.059-.072]$ ), suggesting that most of the paths were similar across the three samples. Significant differences were found for the path of fear of failure to controlled motivation between the Greeks and Germans $\left(\chi^{2}[1]=9.28, p<.01\right)$ and between the Greeks and Belgians $\left(\chi^{2}[1]=6.49, p<.05\right)$. Also, the paths of fear of failure and need for achievement to positive affect significantly differed between the Greeks and the Germans $\left(\chi^{2}[1]=3.86, p<.05\right.$ and $\chi^{2}[1]=9.64, p<.01$, respectively).

The test of group invariance for the study strategies model (Fig. 4) showed also a satisfying fit S-B $\chi^{2}[335]=626.42, p<.01$, $\mathrm{CFI}=.928$, SRMR $=.096$, RMSEA $=.058$ [90\% CI: .051-.065] and differences between Belgians and Germans were found only in the path of autonomous motivation to test strategy $\left(\chi^{2}[1]=7.79\right.$, $p<.01)$ and the path of controlled motivation to anxiety $\left(\chi^{2}[1]=4.12, p<.05\right)$.

Table 2

Measurement and structural models' fit for the three samples.

\begin{tabular}{|c|c|c|c|c|c|c|c|c|}
\hline & $N$ & $d f$ & $\mathrm{~S}-\mathrm{B} \div^{2}$ & $p$ & CFI & SRMR & RMSEA & $90 \% \mathrm{CI}$ \\
\hline \multicolumn{9}{|c|}{ Measurement models } \\
\hline \multicolumn{9}{|c|}{ Affect } \\
\hline Greeks & 430 & 80 & 193.60 & $<.01$ & .944 & .056 & .058 & $.047-.068$ \\
\hline Belgians & 267 & 80 & 187.20 & $<.01$ & .942 & .063 & .071 & $.058-.084$ \\
\hline Germans & 249 & 80 & 161.24 & $<.01$ & .941 & .067 & .064 & $.049-.078$ \\
\hline \multicolumn{9}{|c|}{ Study strategies } \\
\hline Belgians & 265 & 152 & 257.16 & $<.01$ & .957 & .058 & .051 & $.040-.061$ \\
\hline Germans & 248 & 152 & 272.61 & $<.01$ & .927 & .069 & .057 & $.046-.067$ \\
\hline \multicolumn{9}{|c|}{ Structural models } \\
\hline \multicolumn{9}{|c|}{ Affect } \\
\hline Greeks & 430 & 81 & 178.94 & $<.01$ & .952 & .054 & .053 & $.043-.063$ \\
\hline Belgians & 267 & 81 & 170.21 & $<.01$ & .952 & .063 & .064 & $.051-.078$ \\
\hline Germans & 249 & 81 & 159.16 & $<.01$ & .943 & .075 & .062 & $.048-.076$ \\
\hline \multicolumn{9}{|c|}{ Study strategies } \\
\hline Belgian & 267 & 155 & 273.21 & $<.01$ & .951 & .066 & .053 & $.043-.064$ \\
\hline German & 248 & 155 & 281.60 & $<.01$ & .923 & .080 & .058 & $.047-.068$ \\
\hline
\end{tabular}

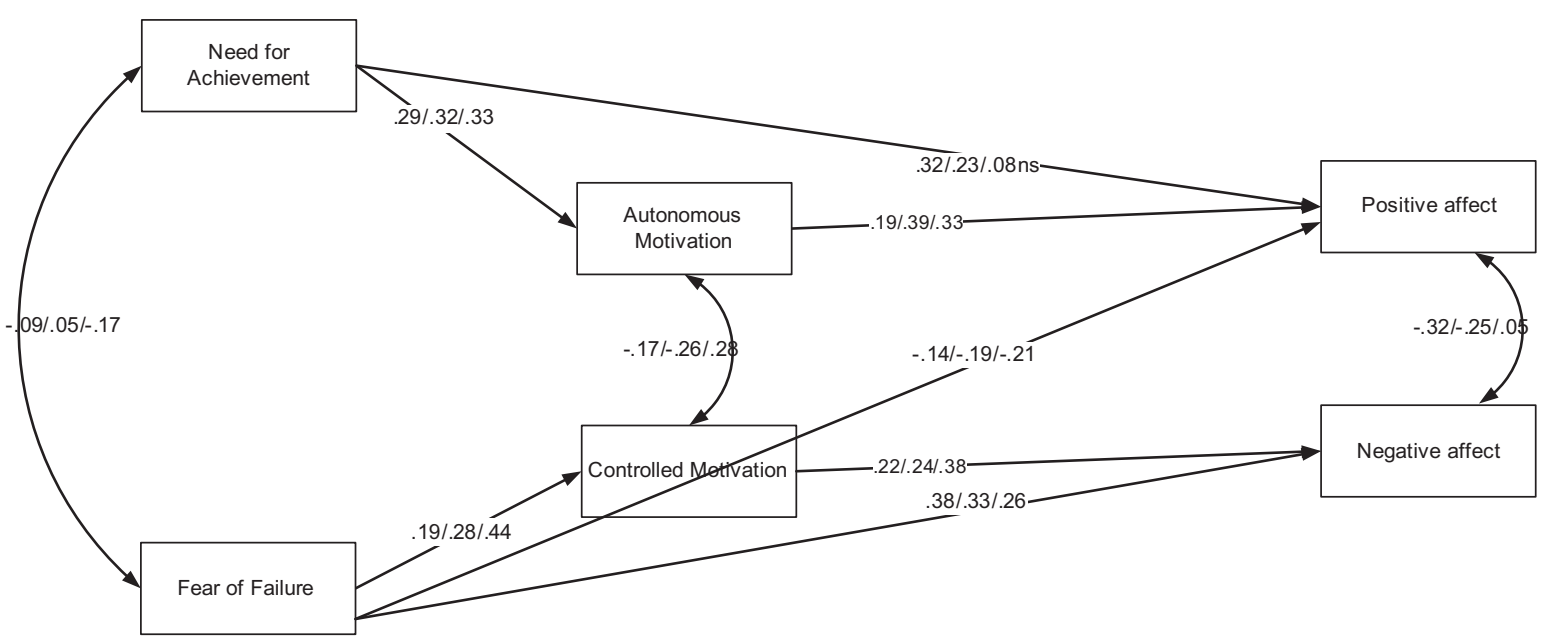

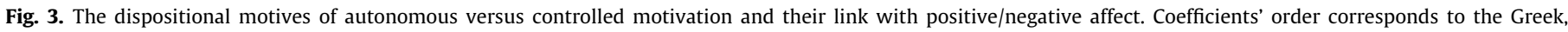
Belgian and German sample. 


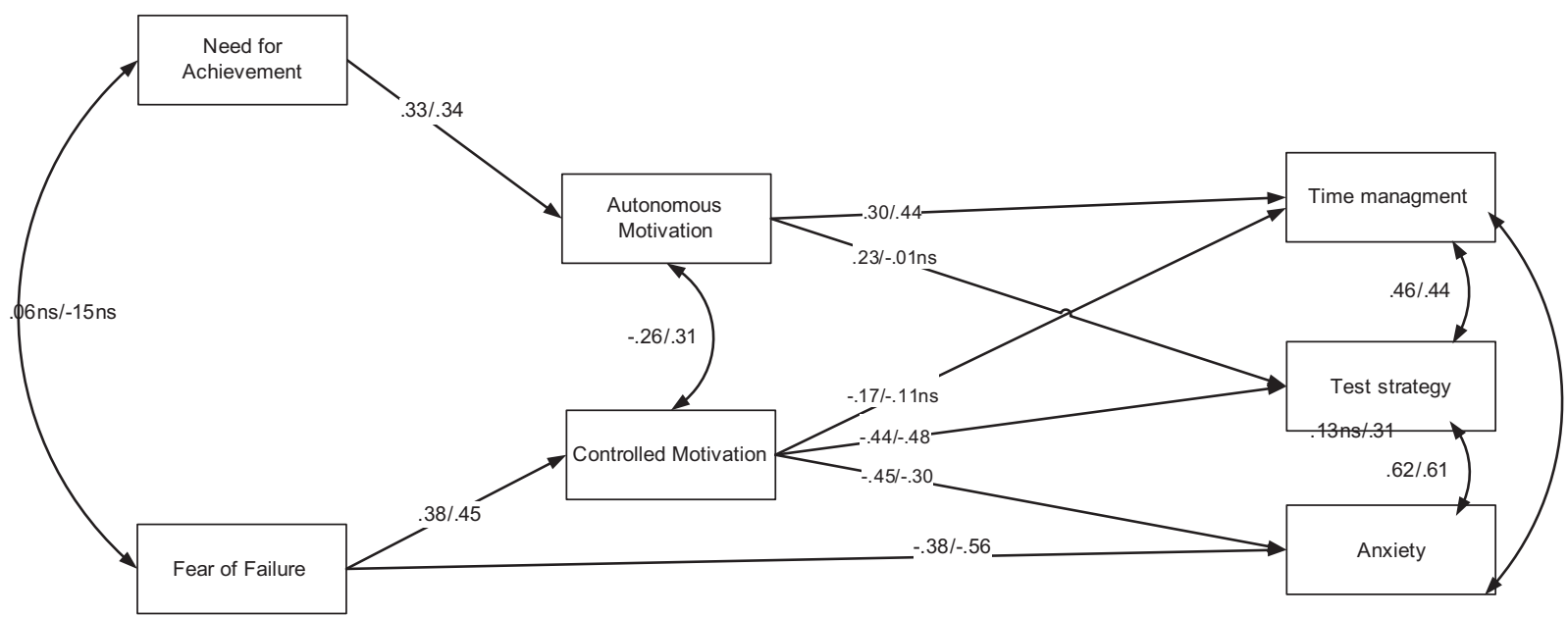

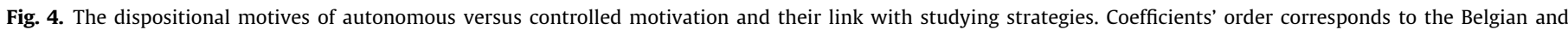
German sample.

\section{Discussion}

In three student samples from different countries and educational settings we found, in a quite consistent way, need for achievement and fear of failure to relate positively to autonomous and controlled motivation, respectively. We found also that autonomous motivation is the channel through which need for achievement related positively to adaptive studying strategies and positive affect, and that controlled motivation is the channel through which fear of failure related positively to negative affect and anxiety and negatively to optimal study strategies.

These findings highlight the approach nature of need for achievement and the aversive character of fear of failure. They further suggest that the achievement dispositions could function as energizers of different qualities of situational motivation. Sheldon and Cooper (2008) argued that a competence-based disposition relates to autonomous motivation when it matches to a competence-based role. Our results further suggest that fear of failure relates to controlled motivation, despite the match of this competence-based disposition to a competence-based role (i.e., the role of student), probably because this disposition has an aversive character. An interesting question for future investigation is whether fear of failure could positively relate to other approach dispositions (e.g., need for affiliation) or whether it coexists only with other avoidance dispositions (e.g., fear of rejection), suggesting thus a generalized tendency to controlled motivation in different settings (achievement, relational, etc.).

Many studies in the SDT tradition have shown across different cultures that social contexts satisfying persons' basic psychological needs lead to autonomous motivation and well-being, irrespective of individual differences. However, our findings coming from three different countries suggest that probably there are acquired tendencies toward either autonomous or controlled motivation that could, apart from the social context, affect the quality of motivation and hence individuals' optimal functioning. Furthermore, the direct associations between achievement motive dispositions and affect suggest that these motives may evoke immediate affective reactions over and above the effects of the social context.

A need supportive environment could be beneficial for all individuals irrespective of their motive dispositions but does such an environment have the same impact on individuals who differ in need for achievement or fear of failure? Can a need-supportive teacher differentiate her practices according to students' dispositions? For example, a student high in fear of failure may need a stronger expression of teacher's likeness to fulfill her need for relatedness compared to a student high in need for achievement. Thus, the evidence provided here that need for achievement and fear of failure relate respectively to autonomous and controlled motivation and through them to psychological functioning, opens a field for much refined research on the effects that need supportive contexts have on persons who differ in achievement motive dispositions.

Our study has revealed two other issues. The first issue concerns the unexpected negative direct relation of fear of failure to positive affect. A careful inspection of the items assessing positive affect in PANAS discloses that they mainly tap high activation and energy. Fear of failure as an inhibitory tendency could not only relate positively to negative affect, as hypothesized, but also negatively to any aspect of vitality. The second issue concerns the strategic cognitive process through which achievement motives manifest in behavior. Up to now, achievement goals have been conceived as the mediating cognitive-motivational process (Elliot, 2006). Our study suggests that autonomous versus controlled situational motivation can operate also as a cognitive-motivational channel to behavior. Given that autonomous and controlled motivation have been recently conceived as the reasons for adopting particular achievement goals (Vansteenkiste et al., 2010), future research could investigate the joint relation of achievement motives to achievement goals and their underlying autonomous and controlling reasons enriching thus the hierarchical model of achievement motivation (Elliot, 2006).

\section{Limitations}

Our cross-sectional design prevents us from claiming a causeeffect phenomenon. Reciprocal relationships among outcomes, situational motivation, and motive dispositions could occur. Another limitation concerns the generalizability of the findings to other achievement settings like sport and work. Furthermore a limitation is posed by the fact that self-reported explicit achievement motives were assessed in the present study and further investigation is required to examine the relation of implicit motives with autonomous versus controlled motivations, affective and learning outcomes as well as with other important outcomes in the achievement domain like performance attainment.

\section{References}

Atkinson, J. W. (1964). An introduction to motivation. New York: Van Nostrand. Atkinson, J. W., \& Feather, N. T. (Eds.). (1966). A theory of achievement motivation. New York: Wiley. 
Bentler, P. M., \& Chou, C. (1987). Practical issues in structural modeling. Sociological Methods E' Research, 16, 78-117.

Caraway, K., Tucker, C. M., Reinke, W. M., \& Hall, C. (2003). Self-efficacy, goal orientation, and fear of failure as predictors of school engagement in high school students. Psychology in the Schools, 4, 417-427.

Deci, E. L., \& Ryan, R. M. (2000). The "What" and "Why" of goal pursuits: Human needs and the self determination of behavior. Psychological Inquiry, 11, 227-268.

Elliot, A. G. (2006). The hierarchical model of approach-avoidance motivation Motivation and Emotion, 30, 111-116. http://dx.doi.org/10.1007/s11031-0069028-7.

Elliot, A. J., \& Church, M. A. (1997). A hierarchical model of approach and avoidance achievement motivation. Journal of Personality and Social Psychology, 72, 218-232. doi:10037/0022-3514.72.1.218.

Elliot, A. J., \& McGregor, H. A. (2001). A $2 \times 2$ achievement goal framework. Journal of Personality and Social Psychology, 80, 501-519. doi:10.1037/00223514.80.3.501.

Elliot, A. J., \& Thrash, T. M. (2004). The intergenerational transmission of fear of failure. Personality and Social Psychology Bulletin, 30, 957-971. http://dx.doi.org/ $10.1177 / 0146167203262024$.

Gray, J. A. (1994). Three fundamental emotion systems. In P. Ekman \& R. J. Davidson (Eds.), The nature of emotion: Fundamental questions (pp. 243-247). New York: Oxford University Press.

Hambleton, R. K. (1994). Guidelines for adapting educational and psychological tests: A progress report. European Journal of Psychological Assessment, 10, 229-240.

Kline, R. B. (2005). Principles and practice in structural equation modeling (2nd ed.). New York: Guilford Press.

Lang, J. W. B., \& Fries, S. (2006). A revised ten item version of achievement motives scale. European Journal of Psychological Assessment, 22, 216-224.

McClelland, D. C. (1987). Human motivation. New York: Cambridge University Press.

McClelland, D. C., Atkinson, J., Clark, R., \& Lowell, E. (1953). The achievement motive. New York: Appleton-Century-Crofts.
Reeve, J., Deci, E. L., \& Ryan, R. M. (2004). Self-determination theory: A dialectical framework for understanding socio-cultural influences on student motivation. In S. Van Etten \& M. Pressley (Eds.), Big theories revisited (pp. 31-60). Greenwich, CT: Information Age Press.

Ryan, R. M., \& Connell (1989). Perceived locus of causality and internalization: Examining reasons for acting in two domains. Journal of Personality and Social Psychology, 57, 749-761.

Ryan, R. M., \& Deci, E. L. (2006). Self-regulation and the problem of human autonomy: Does psychology need choice, self-determination, and will? Journal of Personality, 74, 1557-1585.

Sheldon, K. M., \& Cooper, M. L. (2008). Goal striving within agentic and communal roles: Separate but functionally similar pathways to enhanced well-being. Journal of Personality, 76, 415-447. doi:10.1111/j.1467-6494.2008.00491.x.

Urdan, T. (1997). Achievement goal theory: Past results, future direction. In M. L. Maehr \& P. R. Pintrich (Eds.). Advances in motivation and achievement (Vol. 10, pp. 99-141). Greenwich, CT: JAI Press.

Vandenberg, R. J., \& Lance, C. E. (2000). A review and synthesis of the measurement invariance literature: Suggestions, practices, and recommendations for organizational research. Organizational Research Methods, 3, 4-70.

Vansteenkiste, M., Mouratidis, A., \& Lens, W. (2010). Detaching reasons from aims: Fair play and well-being in soccer as a function of pursuing performanceapproach goals for autonomous or controlling reason. Journal of Sport E Exercise Psychology, 32, 217-224.

Watson, D., Clark, L. A., \& Tellegen, A. (1988). Development and validation of brief measures of positive and negative affect: The PANAS scales. Journal of Personality and Social Psychology, 54, 1063-1070.

Weinstein, C. E., \& Palmer, D. R. (2002). Learning and Study Strategies Inventory (LASSI): User's manual. Clearwater, FL: $\mathrm{H} \& \mathrm{H}$.

Winterbottom, M. R. (1958). The relation of need for achievement to learning experiences in independence and mastery. In J. W. Atkinson (Ed.), Motives in fantasy, action, and society. Princeton: D. Van Nostrand Company Inc. 